\title{
Distributed Architecture for Intelligent Robotic Assembly Part I: \\ Design and Multimodal Learning
}

\author{
Ismael Lopez-Juarez and Reyes Rios-Cabrera
}

\section{Introduction}

\subsection{General Description}

In this chapter we describe the general framework design for a distributed architecture to integrate multiple sensorial capabilities within an intelligent manufacturing system for assembly. We will formally define the model of the $\mathrm{M}_{2} \mathrm{ARTMAP}$ multimodal architecture. We present some simulated results of the model using a public domain multimodal data base. Initial findings have indicated the suitability to employ the M2ARTMAP model in intelligent systems when three or less modalities are involved. Taking into account these results and the M2ARTMAP's modularity it was decided to integrate this model using the CORBA (Component Object Request Broker Architecture) middleware to develop robotic assembly tasks that includes contact force sensing, an invariant object recognition system and natural language processing. This chapter introduces the overall system in the intelligent cell and the task planE ner (SIEM) and the object recognition system (SIRIO) are described in detail in part II and Part III.

Design and experiments of the distributed architecture using a Local Area network (LAN) and an industrial robot KUKA KR-15 to fusion different modalities in a common task are first described. The modalities are: vision, contact force sensing (tactile), and natural language processing using context free \& grammars. The vision modality and force sensing are implemented based on a FuzzyARTMAP neural network and a main coordinator. The testbed for the $\stackrel{\pi}{\pi}$ application and a general distributed environment using CORBA as a mido dleware is described. Later several learning simulations using M2ARTMAP, $\underset{\cup}{\circlearrowleft}$ are presented (Lopez-Juarez \& Ordaz-Hernandez, 2005). The main distributed $\widetilde{\Phi}$ objects are described in detail, the experimentation is presented and the results on analyzed. Finally, future work is proposed. 


\subsection{The architecture}

Robots in unstructured environments have to be adaptable to carry out operation within manufacturing systems. Robots have to deal with its environment, using available sensors and their adaptability will depend on how flexible they are (Wu et al., 1999). To create that system it is necessary to integrate different techniques of artificial intelligence, on-line learning, sensorial capabilities and distributed systems.

This work stands on and improves the design of intelligent agents for assembly (Lopez-Juarez et al., 2005a) by integrating the fusion of different modalities using a distributed system based on CORBA. In the chapter it is designed a distributed architecture where different sensorial modalities, operating systems, middleware and programming languages are integrated to perform mechanical assembly by robots.

A task coordinator referred as the SICT (Sistema Inteligente Coordinador de Tareas, in Spanish), which plans the assembly and general coordination with the vision and system and the assembly system was designed. The SICT is described, it was built using several operating systems (Linux and windows), two ORB's (Object Request Broker) that is ORBit and omniORB and the programming languages are $\mathrm{C}$ and $\mathrm{C}++$. The communication model includes the schema client-server in each module of the system.

\subsection{Description of the Manufacturing System}

The manufacturing system used for experimentation is integrated by a KUKA KR15/2 industrial robot. It also comprises a visual servo system with a ceiling mounted camera as shown in figure 1.

The main operation of the manufacturing system is about the peg-in-hole insertion where, there robot grasps a male component from a conveyor belt and performs the assembly task on a working table where the fixed female component is located. A main coordinator starts the assembly cycle using the vision system that obtains an image from the male component and calculates the object's pose estimation, later it sends information to the coordinator from two defined zones:

Zone 1 which is located on the conveyor belt. The vision system searches for the male component and determines the pose information needed by the robot. 
Zone 2 is located on the working table. Once the vision system locates the female component, it sends the information to the coordinator which executes the assembly with the available information.
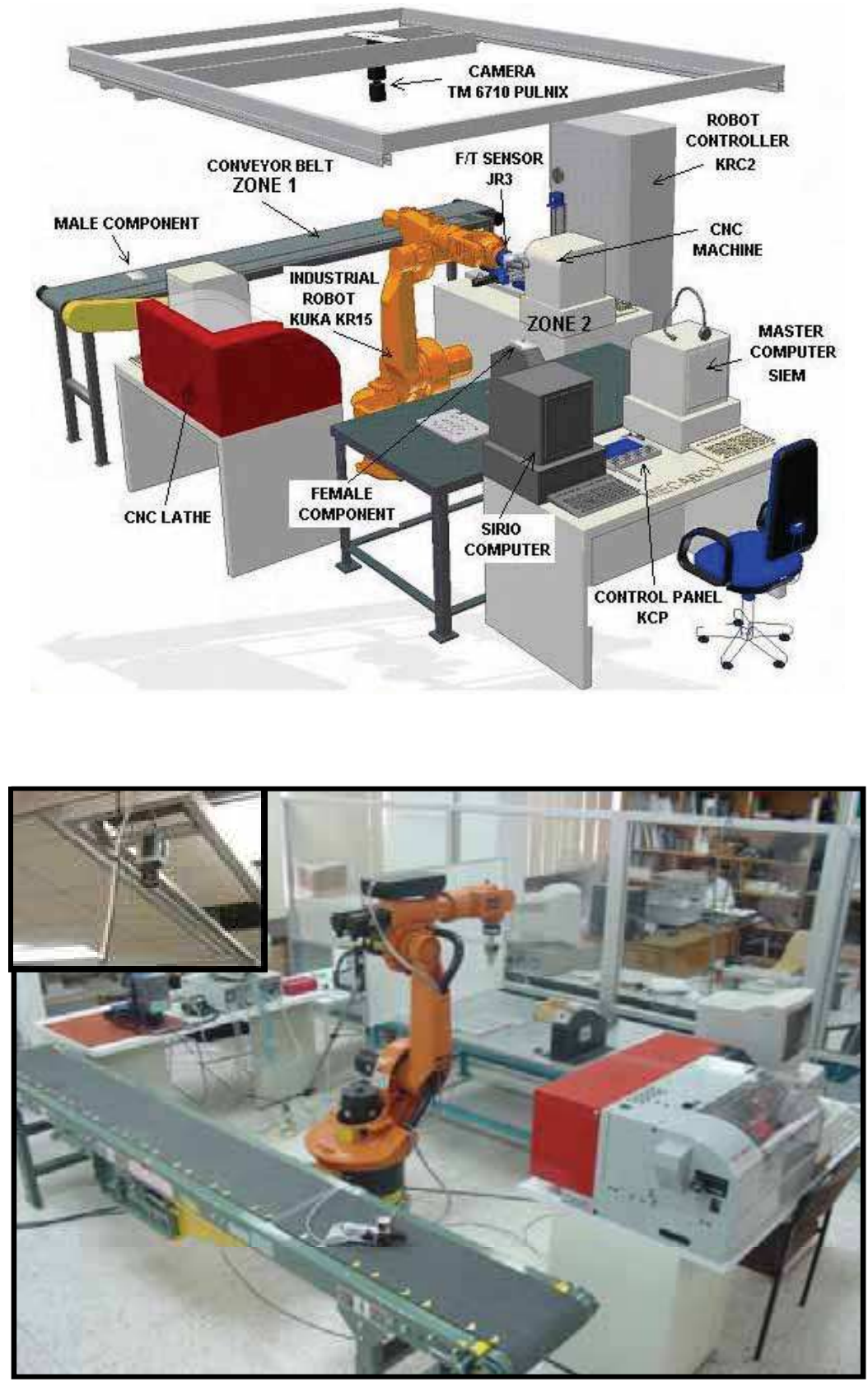

Figure 1. Manufacturing System 
The NNC (Neural Network Controller) for assembly is called SIEM (Sistema Inteligente de Ensamble Mecánico, in Spanish) and is based on a FuzzyARTMAP neural network working in fast learning mode (Carpenter et al., 1992). The vision system, called SIRIO (Sistema Inteligente de Reconocimiento Invariante de Objetos), also uses the same neural network to learn and classify the assembly components. The SIRIO was implemented with a high speed camera CCD/B\&W, PULNIX 6710, with 640x480 resolution. The camera movement on the $\mathrm{X}-\mathrm{Y}$ plane was implemented using a 2D positioning system.

\section{State of the Art}

\subsection{Distributed Robotic Systems}

The concept of distributed systems and other technologies recently have made possible the creation of new application called "Networked Robot Systems". The reduction in cost is one of the several advantages of creating distributed systems. This is mainly for the use and creation of standard components and infrastructures (Amoretti, 2004); in addition the CORBA standard solves the heterogeneity problem which is found in the robotic systems in a network. It permits the interaction and interoperability of different systems developed with different technologies, programming languages, operation systems or hardware.

Currently, the development of robot systems base on distributed components is being developed by different researchers. In (Amoretti et al., 2003), Michael Amoretti et al., present an analysis of three techniques for data distributing of sensors through the network. The first technique is called Callback, where the clients call a method of a server and at the same time send an object reference to inform the server to which client has to send the answer and information. When the server finishes the asked task, it checks the object number to which it has to send the results. The second technique is based on the services or events of CORBA. Where the servers produce events and the clients receive them using an event channel. The event channel conducts the events of the servers to the clients, without having information about the clients and vice versa. In spite of the advantages of the event channel, when it is used, it generates negative aspects, such as the data type, since it has to be of type "any" or IDL, and it makes the communication not very secure. Clients have to convert the data 
to their respective type and another problem of the event channel is that it could saturate the network, since it does not have an event filter and sends all messages to all clients. The event services does not contemplate the use of QoS (Quality of Service), related with the priority, liability and order.

The third technique is based on the Notification Service of CORBA. It is an improvement of the Service of Events. The most important improvement includes the use of QoS. In the notification service each client uses the events in which it is interested.

The implementation of the Callback technique offers a better performance than the others; however the ones based on the event channel are easily scalable. The technique used in our research is Callback since the number of clients, is not bigger of 50 .

In (Amoretti, 2004) it is proposed a robotic system using CORBA as communication architecture and it is determined several new classes of telerobotic applications, such as virtual laboratories, remote maintenance, etc. which leads to the distributed computation and the increase of new developments like teleoperation of robots. They used a distributed architecture supporting a large number of clients, written in $\mathrm{C}++$ and using CORBA TAO as middleware, but it is an open architecture, and it does not have intelligence, just remote execution of simple tasks.

In (Bottazzi et al., 2002), it is described a software development of a distributed robotic system, using CORBA as middleware. The system permits the development of Client-Server application with multi thread supporting concurrent actions. The system is implemented in a laboratory using a manipulator robot and two cameras, commanded by several users. It was developed in $\mathrm{C}++$ and using TAO.

In (Dalton et al., 2002), several middleware are analyzed, CORMA, RMI (Remote Method Invocation) and MOM (Message Oriented Middleware). But they created their own protocol based on MOM for controlling a robot using Internet.

In (Jia et al., 2002), (Jia et al., 2003) it is proposed a distributed robotic system for telecare using CORBA as communication architecture. They implemented three servers written in $\mathrm{C}++$, the first one controls a mobile robot, the second one is used to control an industrial robot and the last one to send real time video to the clients. On the other side of the communication, it is used a client based on Web technology using Java Applets to make easier the use of the system in Internet. In (Jia et al., 2003), the authors increased the number of servers 
available in the system, with: a user administrator and a server for global positioning on the working area.

In (Corona-Castuera \& Lopez-Juarez, 2004) it is discussed how industrial robots are limited in terms of a general language programming that allows learning and knowledge acquisition, which is probably, one of the reasons for their reduced use in the industry. The inclusion of sensorial capabilities for autonomous operation, learning and skill acquisition is recognized. The authors present an analysis of different models of Artificial Neuronal Networks (ANN) to determine their suitability for robotic assembly operations. The FuzzyARTMAP ANN presented a very fast response and incremental learning to be implemented in the robotic assembly system. The vision system requires robustness and higher speed in the image processing since it has to perceive and detect images as fast as or even faster than the human vision system. This requirement has prompted some research to develop systems similar to the morphology of the biological system of the human being, and some examples of those systems, can be found in (Peña-Cabrera \& Lopez-Juarez, 2006), (PeñaCabrera et al., 2005), where they describe a methodology for recognising objects based on the Fuzzy ARTMAP neural network.

\subsection{Multimodal Neural Network}

A common problem in working in multimodality for robots systems is the employment of data fusion or sensor fusion techniques (Martens, S. \& Gaudiano, P., 1998 and Thorpe, J. \& Mc Eliece, R., 2002). Multimodal pattern recognition is presented in (Yang, S. \& Chang, K.C., 1998) using Multi-Layer Perceptron (MLP). The ART family is considered to be an adequate option, due to its superior performance found over other neural network architectures (Carpenter, G.A. et al., 1992). The adaptive resonance theory has provided ARTMAP-FTR (Carpenter, G.A. \& Streilein, W.W, 1998), MART (Fernandez-Delgado, M \& Barro Amereiro, S, 1998), and Fusion ARTMAP (Asfour, et al., 1993) - among others - to solve problems involving inputs from multiple channels. Nowadays, G.A. Carpenter has continued extending ART family to be employed in information fusion and data mining among other applications (Parsons, O. \& Carpenter, G.A, 2003).

The Mechatronics and Intelligent Manufacturing Systems Research Group (MIMSRG) at CIATEQ performs applied research in intelligent robotics, concretely in the implementation of machine learning algorithms applied to as- 
sembly tasks - using distributed systems contact forces and invariant object recognition. The group has obtained adequate results in both sensorial modalities (tactile and visual) in conjunction with voice recognition, and continues working in their integration within an intelligent manufacturing cell. In order to integrate other sensorial modalities into the assembly robotic system, an ART-Based multimodal neural architecture was created.

\section{Design of the Distributed System}

\subsection{CORBA specification and terminology}

The CORBA specification (Henning, 2002), (OMG, 2000) is developed by the OMG (Object Management Group), where it is specified a set of flexible abstractions and specific necessary services to give a solution to a problem associated to a distributed environment. The independence of CORBA for the programming language, the operating system and the network protocols, makes it suitable for the development of new application and for its integration into distributed systems already developed.

It is necessary to understand the CORBA terminology, which is listed below:

A CORBA object is a virtual entity, found by an ORB (Object Request Bro ker, which is an ID string for each server) and it accepts petitions from the clients.

A destine object in the context of a CORBA petition, it is the CORBA ob ject to which the petition is made.

A client is an entity which makes a petition to a CORBA object.

A server is an application in which one or more CORBA objects run.

A petition is an operation invocation to a CORBA object, made by a client.

An object reference is a program used for identification, localization and di rection assignment of a CORBA object.

A server is an identity of the programming language that imple ments one or more CORBA objects.

The petitions are showed in the figure 2: it is created by the client, goes through the ORB and arrives to the server application. 


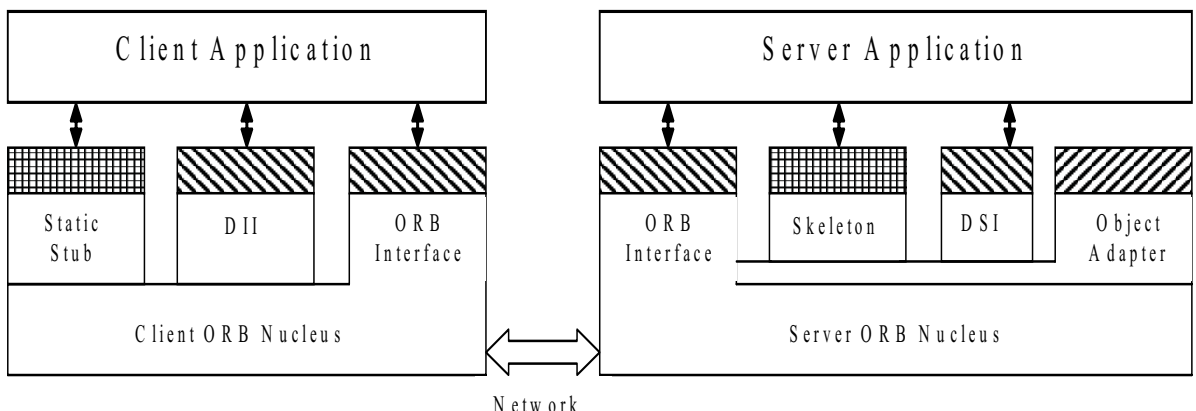

ID Dependent

Figure 2. Common Object Request Broker Architecture ( COBRA)

- The client makes the petitions using static stub or using DII (Dynamic Invocation Interface). In any case the client sends its petitions to the ORB nucleus linked with its processes.

- The ORB of the client transmits its petitions to the ORB linked with a server application.

- The ORB of the server redirect the petition to the object adapter just created, to the final object.

- The object adapter directs its petition to the server which is implemented in the final object. Both the client and the sever, can use static skeletons or the DSI (Dynamic Skeleton Interface)

- The server sends the answer to the client application.

In order to make a petition and to get an answer, it is necessary to have the next CORBA components:

Interface Definition Language (IDL): It defines the interfaces among the programs and is independent of the programming language.

Language Mapping: it specifies how to translate the IDL to the different pro gramming languages.

Object Adapter: it is an object that makes transparent calling to other ob jects.

Protocol Inter-ORB: it is an architecture used for the interoperability among different ORBs.

The characteristics of the petitions invocation are: transparency in localization, transparency of the server, language independence, implementation, architecture, operating system, protocol and transport protocol. (Henning, 2002). 


\subsection{Architecture and Tools}

The aim of having a coordinator, is to generate a high level central task controller which uses its available senses (vision and tactile) to make decisions, acquiring the data on real time and distributing the tasks for the assembly task operation.

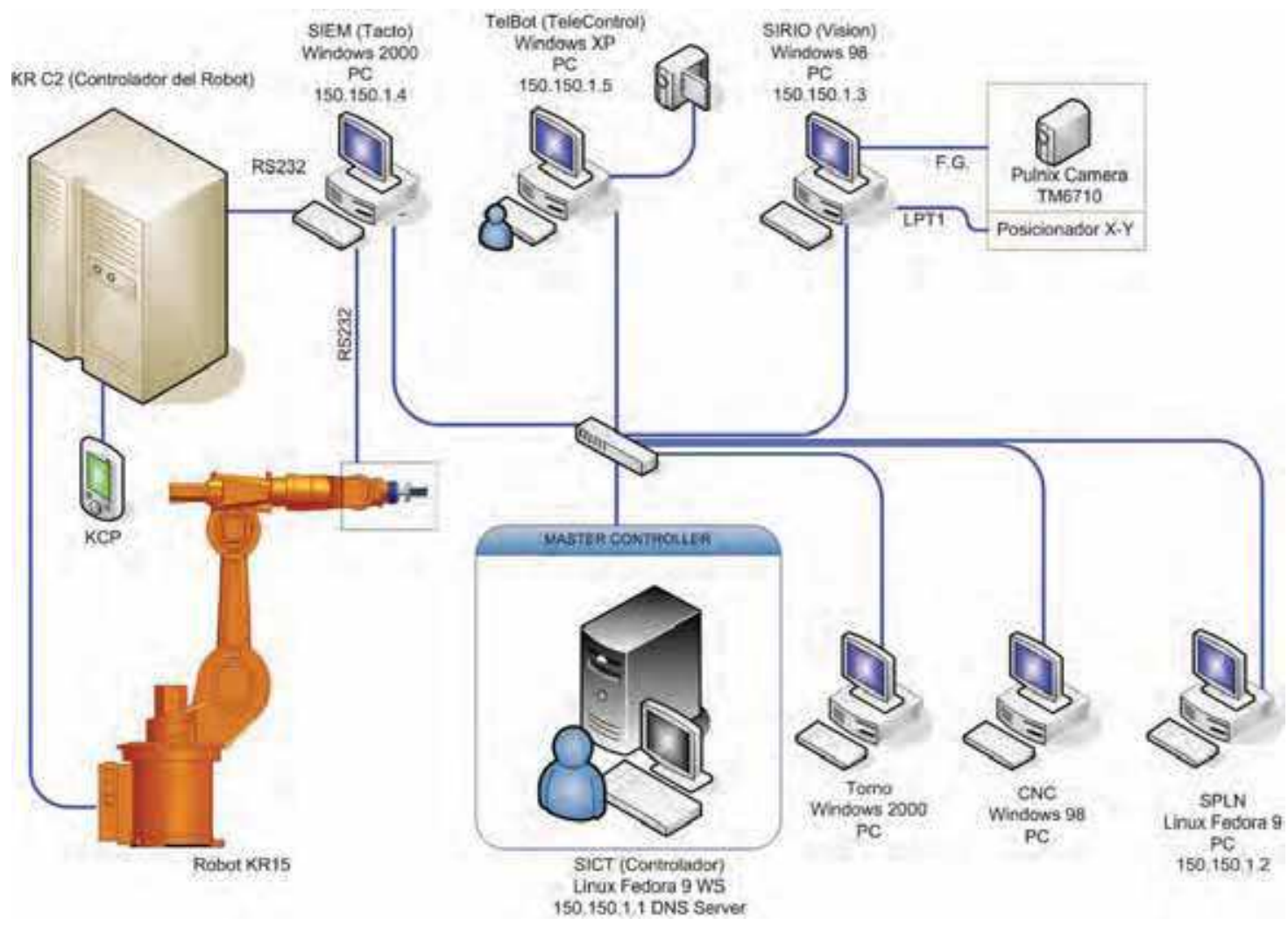

Figure 3. Distributed Manufacturing Cell

Figure 3 shows the configuration of the network and the main components of the distributed cell, however, the active ones are: SIRIO, SIEM, SICT and SPLN. The system works using a multiple technology architecture where different operating systems, middleware, programming language and graphics tools were used, as it can be seen in figure 4. It describes the main modules of the manufacturing cell SIEM, SIRIO, SICT and SPLN. 


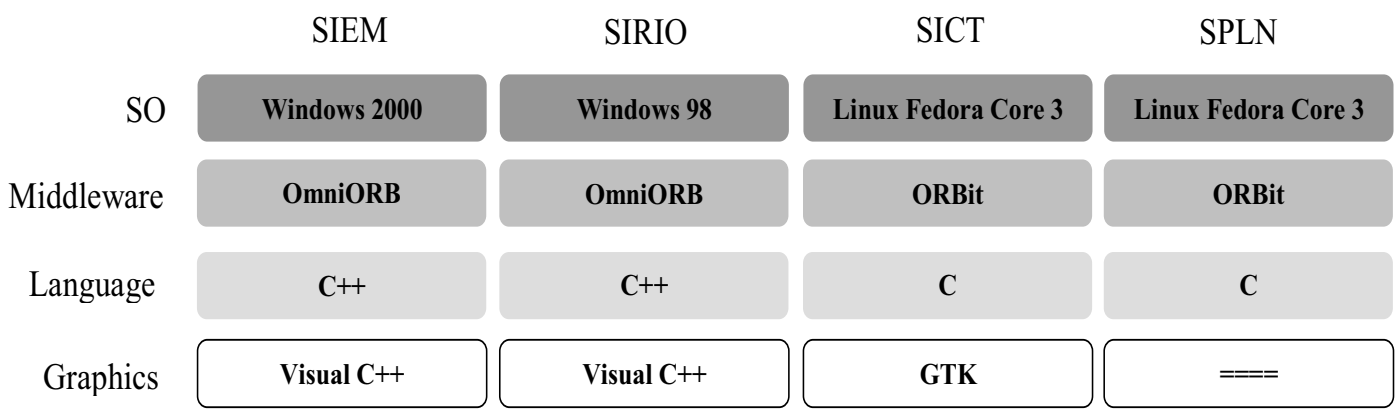

Figure 4. Different operating systems, middleware, programming languages and graphic tools.

The architecture of the distributed system uses a Client/Server in each module. Figure 5 shows the relationship client-server in SICT for each module. But with the current configuration, it is possible a relationship from any server to any client, since they share the same network. It is only necessary to know the name of the server and obtain the IOR (Interoperable Object Reference).

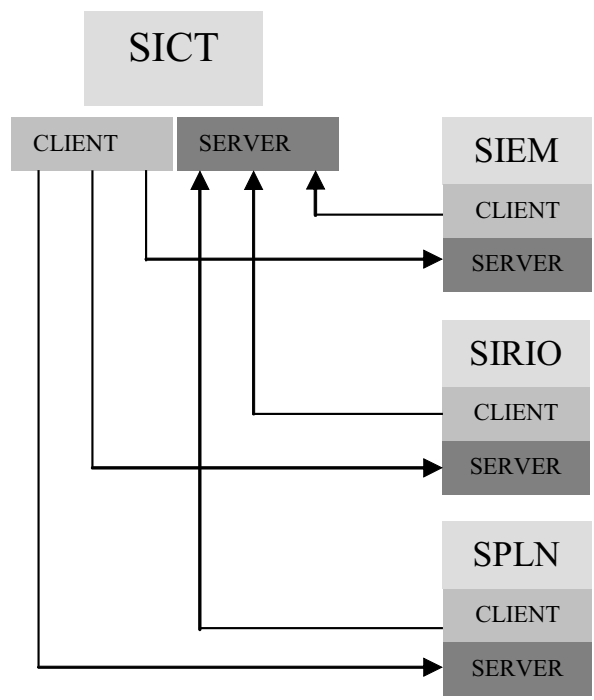

Figure 5. Client/server architecture of the distributed cell

The interfaces or IDL components needed to establish the relations among the modules SICT, SIRIO, SIEM and SPLN are described in the following section. 


\section{Servers Description}

\subsection{SICT Interface}

This module coordinates the execution of task in the servers (this is the main coordinator). It is base in Linux Fedora Core 3, in a Dell Workstation and written in $C$ language using gcc and ORBit 2.0. For the user interaction of these modules it was made a graphic interface using GTK libraries.

The figure 6 shows the most important functions of the IDL.

\section{$<<$ Interface $>>$ \\ SICT IDL}

+ EndSIRIO(in finalStatus: long(idl)): void

+ EndSIEM(in finalStatus: long(idl)): void

+ EndSPLN(in finalStatus:

+ ExecuteSPLNCommand(in command: long(idl), in parameters: string(idl)): void

+ GetStatus(): CurrentStatus

$\cdots$

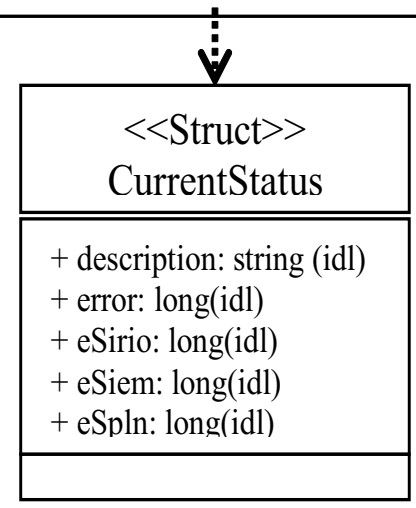

Figure 6. SICT Interface

iSICT: the functions of this interface are used for SIRIO and SIEM to indicate that they have finished a process. Each system sends to SICT a finished process acknowledgement of and the data that they obtain. SICT makes the decisions about the general process. The module SPLN uses one of the functions of SICT to ask it to do a task, sending the execution command with parameters. The figure 7 shows the main screens of the coordinator. 

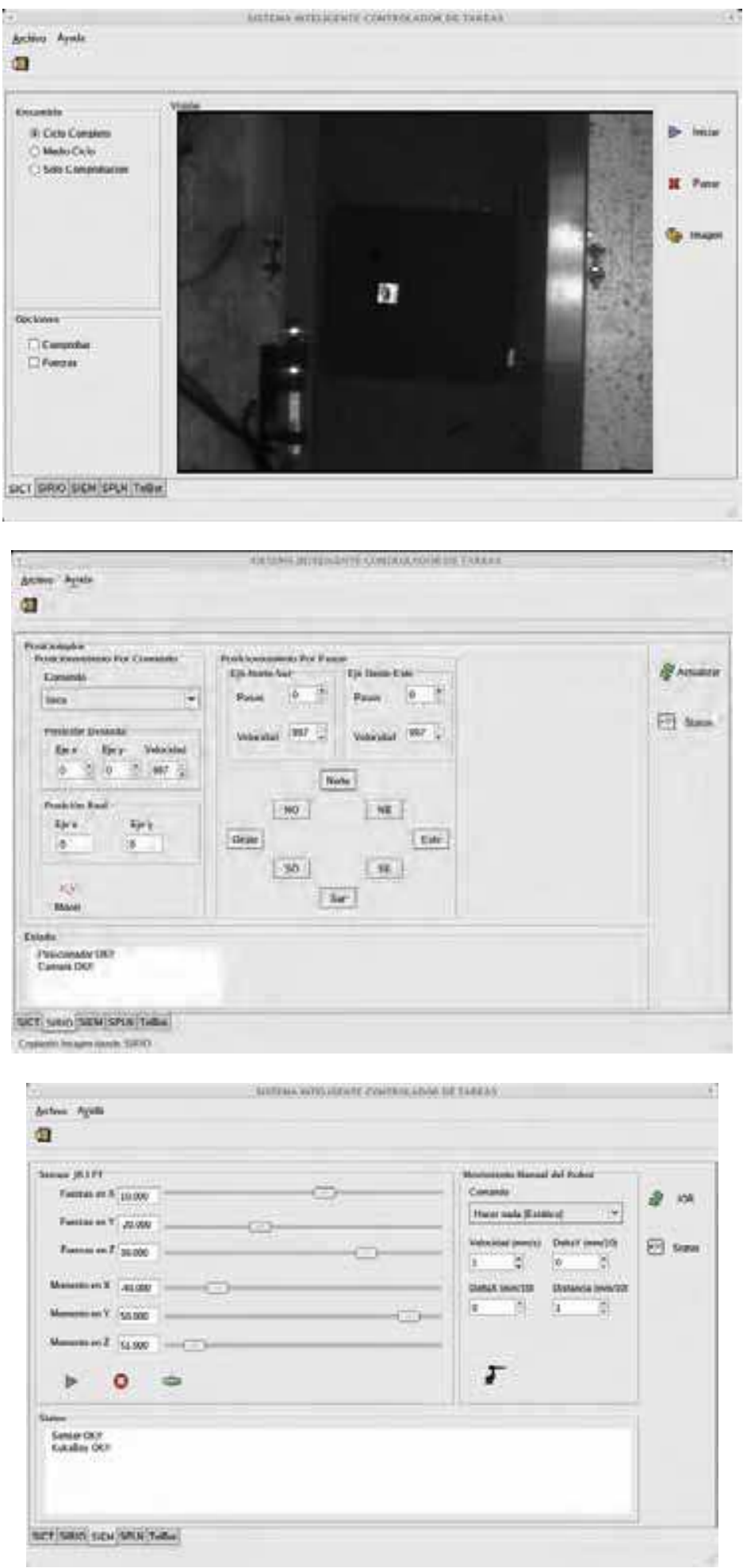

Figure 7. Controls of the interface SICT 


\subsection{SIRIO Interface}

This system is the vision sense of the robot, using a camera Pulnix TM6710, which can move around the cell processing the images in real time. SIRIO carries out a process based on different marks. It calculates different parameters of the working pieces, such as orientation, shape of the piece, etc. This system uses Windows 98 and is written in Visual C++ 6.0 with OmniORB as middleware.

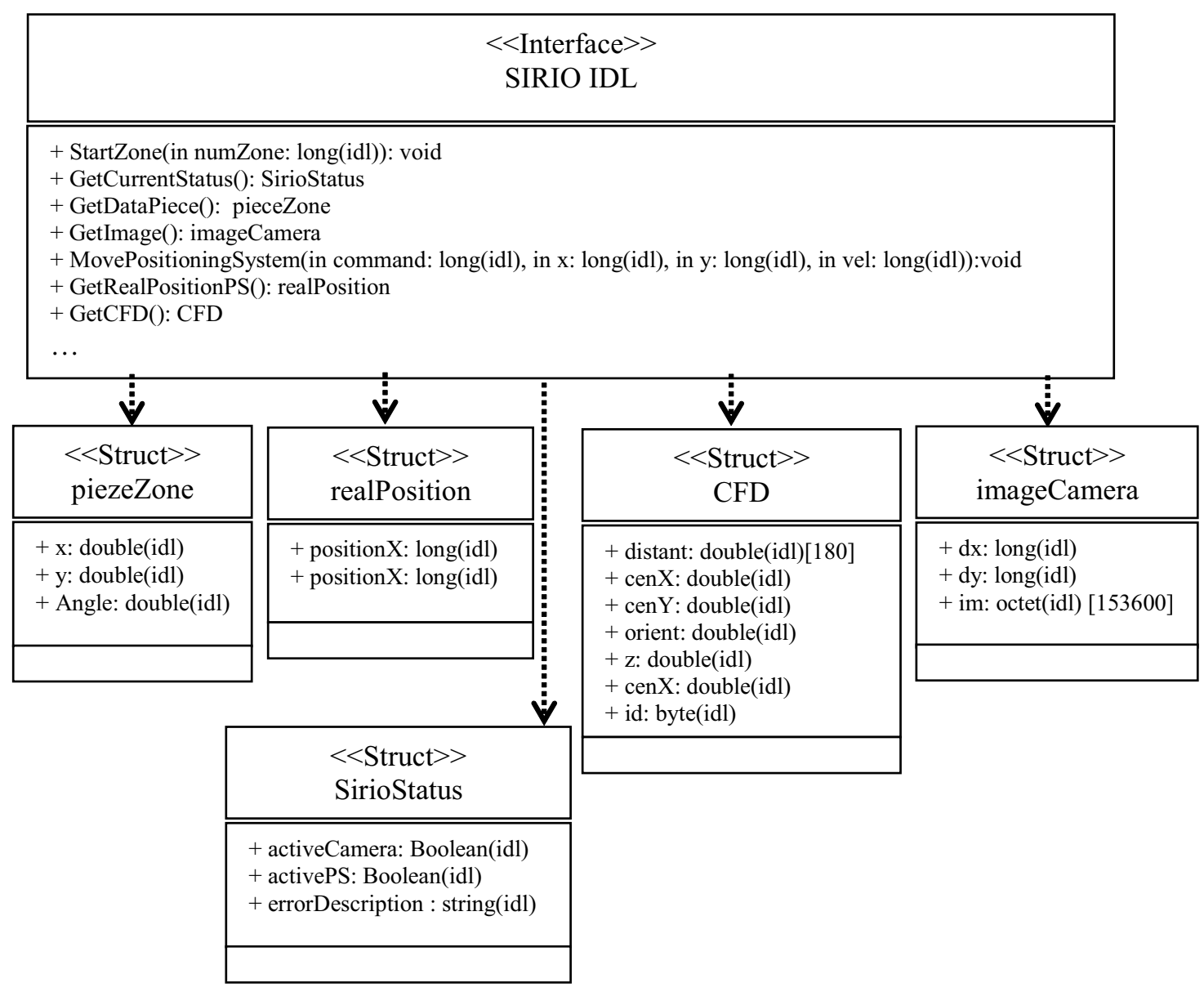

Figure 8. SIRIO Interface

iSIRIO interface contains functions used by the SICT to initialize the assembly cycle, to obtain the status of SIRIO, an image in real time or to move the camera over the manufacturing cell. The function StartZone, calls a process located in SIRIO to make the positioning system move to different zones of the cell. The function GetCurrentStatus is used to get the current status of the SIRIO 
module, and it sends information about the hardware. When SIRIO finishes processing an image it sends an acknowledgement to SICT and this ask for the data using the function GetDataPiece which gives the position and orientation of the piece that the robot has to assembly.

The function GetImage gives a vector containing the current frame of the camera and its size. The function MovePositioningSystem is used by SICT to indicate to SIRIO where it has to move the camera. The movements are showed in table 1, where it executes movements using the variables given by the client that called the function.

$\begin{array}{llllllll}\text { Tabla 1. } & \text { Command } & \text { Tabla 2. } & \text { X } & \text { Tabla 3. } & \text { Y } & \text { Tabla 4 } & \text { Speed } \\ \text { Tabla 5. } & \text { Start } & \text { Tabla 6. } & \text { No } & \text { Tabla 7. } & \text { No } & \text { Tabla 8. } & \text { Yes } \\ \text { Tabla 9. } & \text { Zone 1 } & \text { Tabla 10. } & \text { No } & \text { Tabla 11. } & & \text { Tabla 12. } & \text { Yes } \\ \text { Tabla 13 } & \text { Zone 2 } & \text { Tabla 14. } & \text { No } & \text { Tabla 15. } & \text { No } & \text { Tabla 16. } & \text { Yes } \\ \text { Tabla 17 } & \begin{array}{c}\text { Moves } \\ \text { to }(\mathrm{x}, \mathrm{y})\end{array} & \text { Tabla 18. } & \text { Yes } & \text { Tabla 19. } & \text { Yes } & \text { Tabla 20. } & \text { Yes } \\ & & & & & & \end{array}$

Table 1. Commands for moving the positioning system.

The function GetRealPositonPS obtains the position $(\mathrm{x}, \mathrm{y})$ where the positioning system is located.

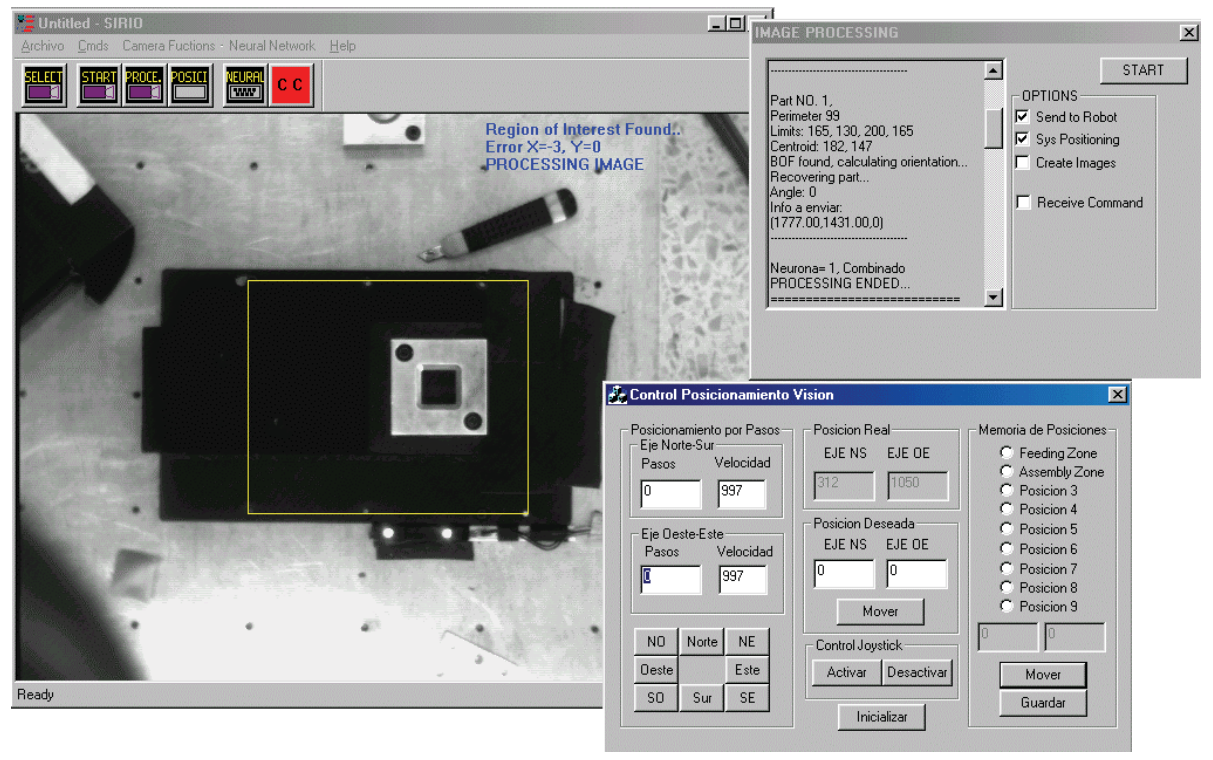

Figure 9. SIRIO main scream 
The last function GetCFD(), gets the CFD (Current Frame Descriptor) of a piece. The piece is always the last the system used, or the one being used. The CFD contains the description of a piece. For more details the reader is referred to part III of this work (Peña-Cabrera, M. \& Lopez-Juarez, I, 2006).

\subsection{SIEM Interface}

This contact force sensing system resembles the tactile sense, and uses a JR3 Force/Torque $(\mathrm{F} / \mathrm{M})$ sensor interacting with the robot and obtaining contact information from the environment. SIEM is used when the robot takes a piece from the conveyor belt or when or when an assembly is made. The robot makes the assemblies with incremental movements and in each movement, SIEM processes and classifies the contact forces around the sensor, using the neural network to obtain the next direction movement towards the assembly. SIEM is implemented in an industrial parallel computer using Windows 2000 and written in Visual C++ 6.0 and OmniORB.

Figure 10 shows the main functions of the IDL SIEM.

\begin{tabular}{|c|c|c|}
\hline \multicolumn{3}{|c|}{$\begin{array}{c}<<\text { Interface }>> \\
\text { SIEM IDL }\end{array}$} \\
\hline \multicolumn{3}{|c|}{$\begin{array}{l}\text { + MoveRobot(in numZone: long(idl), in Data: pieceZone): void } \\
\text { + GetCurrentStatus(): SiemStatus } \\
\text { + GetCurrentForces(): forcesReading } \\
\text { + RobotMoveCommand(in command: long(idl), in DeltaX: long(idl), in DeltaY: long(idl), in Speed: long(idl), in Distance : long(idl) } \\
\text {.. }\end{array}$} \\
\hline$\dot{v}$ & $\dot{V}$ & $\dot{v}$ \\
\hline $\begin{array}{l}<<\text { Struct }>> \\
\text { piezeZone }\end{array}$ & $\begin{array}{l}<<\text { Struct }>> \\
\text { siemStatus }\end{array}$ & $\begin{array}{c}<<\text { Struct }>> \\
\text { forcesReading }\end{array}$ \\
\hline $\begin{array}{l}\text { + x: double(idl) } \\
\text { + y: double(idl) } \\
\text { + Angle: double(idl) }\end{array}$ & $\begin{array}{l}\text { + activeRobot: double(idl) } \\
\text { + activeSensorFT: long(idl) } \\
\text { + description: string(idl) }\end{array}$ & $\begin{array}{l}\text { + vector: double(idl) [6] } \\
\text { + Flimit: double(idl) } \\
\text { + Mlimit: double(idl) }\end{array}$ \\
\hline
\end{tabular}

Figure 10. SIEM Interface

iSIEM: SICT moves the robot thought SIEM, obtains the components state and the reading of the current forces in the different zones of the manufacturing cell. The function GetCurrentStatus, is used to obtain the status of the hard- 
ware (sensor F/T and communication) and software of the SIEM. The function MoveRobot is used when SIRIO finishes an image processing and sends information about the piece to the task coordinator.

The GetCurrentForces function helps the SICT to acquire force data from the JR3 Force/Torque $(\mathrm{F} / \mathrm{T})$ sensor at a selected sampling rate. This function returns a data vector with information about the force and torque around $\mathrm{X}, \mathrm{Y}$ and $\mathrm{Z}$ axis.

Finally, the function RobotMoveCommand is used by the SICT to indicate appropriate motion commands to SIEM. These types of motions are shown in Table 2. Here is also shown the required information for each command (distance, speed). The windows dialog is shown in Figure 11.

\begin{tabular}{|c|c|c|}
\hline Command & Distance & Speed \\
\hline Do nothing [static] & No & No \\
\hline Home position & No & No \\
\hline Coordinates world & No & No \\
\hline Tool Coordinates & No & No \\
\hline $\begin{array}{c}\text { Axe by Axe Coordi- } \\
\text { nates }\end{array}$ & No & No \\
\hline Base Coordinates & No & No \\
\hline Movement X+ & Yes & Yes \\
\hline Movement X- & Yes & Yes \\
\hline Movement Y+ & Yes & Yes \\
\hline Movement Y- & Yes & Yes \\
\hline Movement Z+ & Yes & Yes \\
\hline Movement Z- & Yes & Yes \\
\hline Rotation $\mathrm{X}^{+}$ & Yes & Yes \\
\hline Rotation X- & Yes & Yes \\
\hline Rotation $\mathrm{Y}+$ & Yes & Yes \\
\hline Rotation Y- & Yes & Yes \\
\hline Rotation Z+ & Yes & Yes \\
\hline Rotation Z- & Yes & Yes \\
\hline Diagonal $\mathrm{X}+\mathrm{Y}+$ & Yes & Yes \\
\hline
\end{tabular}

\begin{tabular}{|c|c|c|}
\hline Command & Distance & Speed \\
\hline Diagonal X+Y- & Yes & Yes \\
\hline Diagonal X-Y+ & Yes & Yes \\
\hline Diagonal X-Y- & Yes & Yes \\
\hline $\begin{array}{c}\text { Finish Communica- } \\
\text { tion }\end{array}$ & No & No \\
\hline $\begin{array}{c}\text { Open griper } \\
\text { No griper }\end{array}$ & No & No \\
\hline Rotation A1+ & Yes & Yes \\
\hline Rotation A1- & Yes & Yes \\
\hline Rotation A2+ & Yes & Yes \\
\hline Rotation A2- & Yes & Yes \\
\hline Rotation A3+ & Yes & Yes \\
\hline Rotation A3- & Yes & Yes \\
\hline Rotation A4+ & Yes & Yes \\
\hline Rotation A4- & Yes & Yes \\
\hline Rotation A5+ & Yes & Yes \\
\hline Rotation A5- & Yes & Yes \\
\hline Rotation A6+ & Yes & Yes \\
\hline Rotation A6- & Yes & Yes \\
\hline \multicolumn{2}{|l}{} & \\
\hline
\end{tabular}

Table 2. Commands to move the robot 


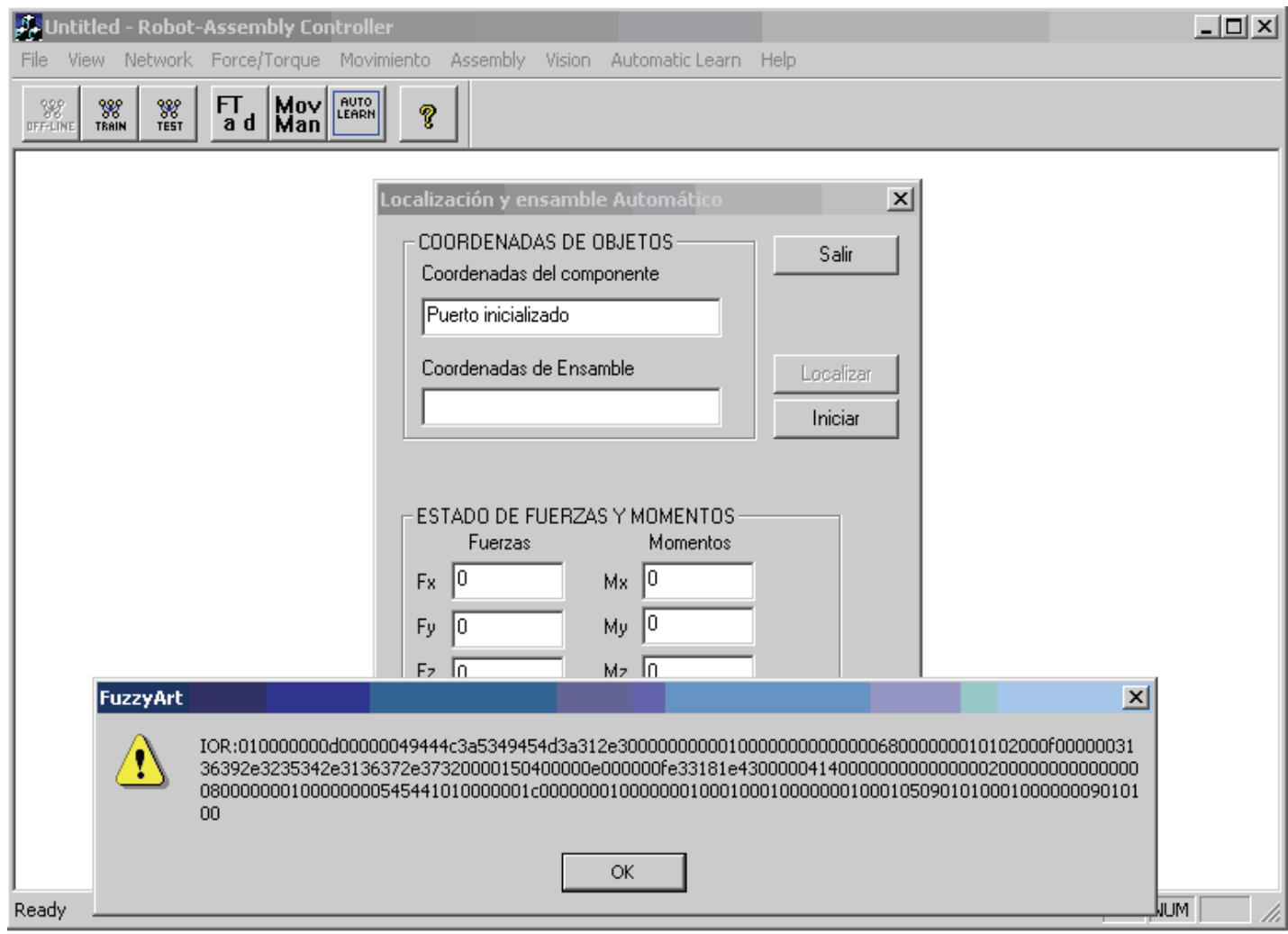

Figure 11. SIEM screen

\subsection{SPLN Interface}

The system provides a user interface to receive directions in natural language using natural language processing and context free grammars. After the instruction is given, a code is generated to execute the ordered sentences to the assembly system. The SPLN is based on Linux Fedora Core 3 operating system using a PC and programmed in C language and a $\mathrm{g}++$, Flex, Yacc and ORBit 2.0. compiler.

iSPLN: This interface receives the command status from the SPLN, and gets the system's state as it is illustrated in Figure 12.

EndedTask is used by the SICT to indicate the end of a command to the SPLN like the assembly task. As a parameter, SICT sends to SPLN the ending of the task. GetStatus function serves to obtain the general state of the SPLN. 


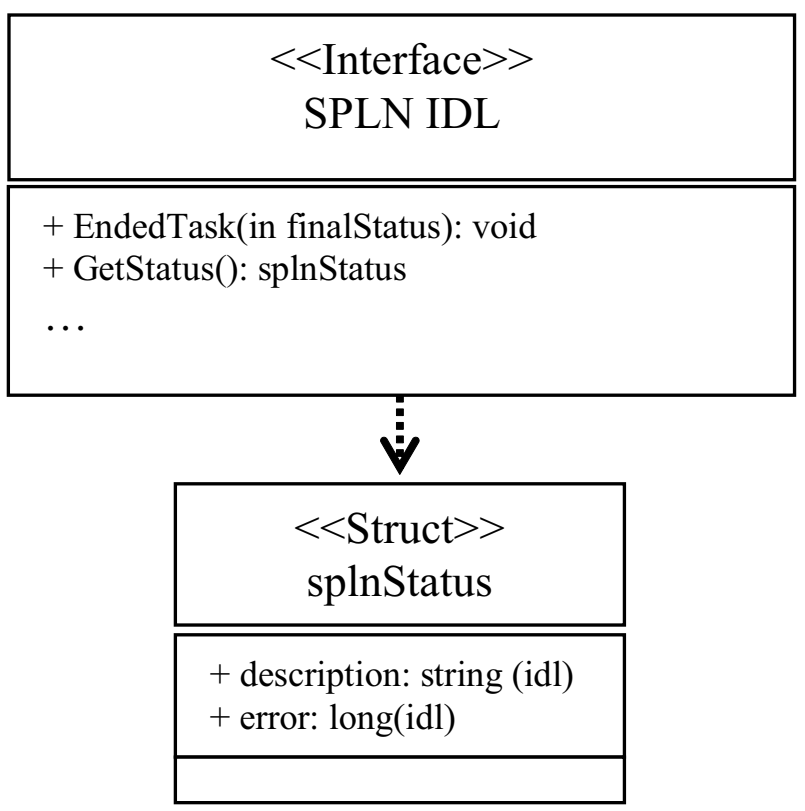

Figure 12. Interface SPLIN

\section{Multimodal Architecture.}

We have described so far the architecture of the distributed system, where each module has its own FuzzyARTMAP neural network, its own KB (Knowledge Base) and configuration. The architecture showed in figure 13 shows the current architecture module $\mathrm{M}_{2} \mathrm{ARTMAP}$. Currently, there is a coordinator substituting the Integrator and Predictor in the upper level. M2ARTMAP has demonstrated to be faster in training and learning than a single Fuzzy ARTMAP making a fusion of all senses at the same time, for more details see (Lopez-Juarez et al., 2005).

- Predictor

- Modality is the final prediction component that uses modalities' predictions.

is the primary prediction component that is composed by an artificial neural network (ANN), an input element (Sensor), a configuration element (CF), and a knowledge base (KB). 
- Integrator is the component that merges the modalities' predictions by inhibiting those that are not relevant to the global prediction activity, or stimulating those who are consid ered of higher reliability - in order to facilitate the Pre dictor's process.

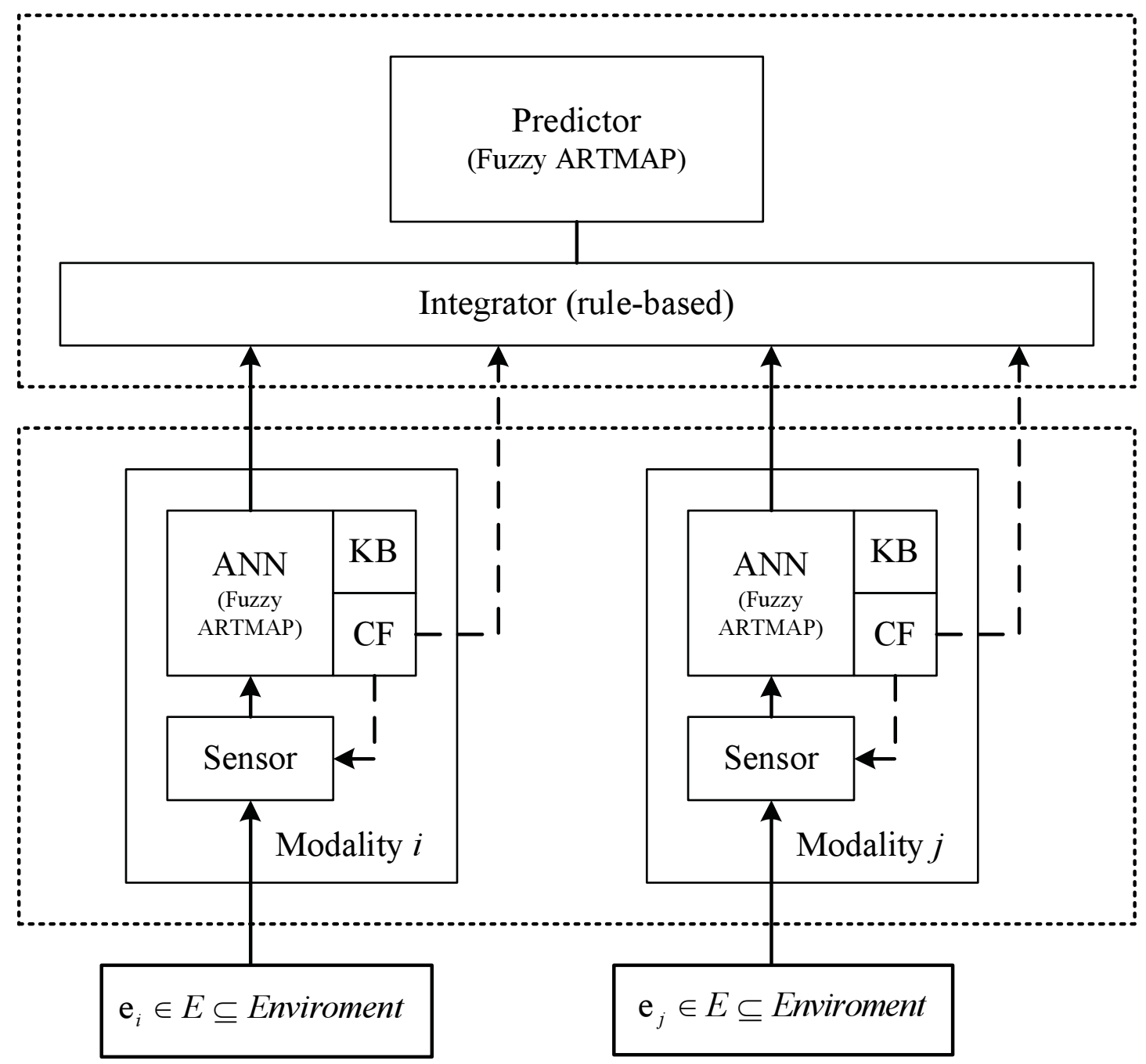

Figure 13. Multimodal neural architecture, M2ARTMAP, integrated by three main components organized in two layers: Modality (several found at the lower layer), Predictor and Integrator (at the upper layer) 


\subsection{Multimodal simulations}

Fuzzy ARTMAP and M2ARTMAP systems were simulated using the Quadruped Mammal database (Ginnari, J.H.; et al., 1992) which represents four mammals (dog, cat, giraffe, and horse) in terms of eight components (head, tail, four legs, torso, and neck). Each component is described by nine attributes (three location variables, three orientation variables, height, radius, and texture), for a total of 72 attributes. Each attribute is modelled as a Gaussian process with mean and variance dependent on the mammal and component (e.g. the radius of a horse's neck is modelled by a different Gaussian from that of a dog's neck or a horse's tail). At this point, it is important to mention that Quadruped Mammal database is indeed a structured quadruped mammal instances generator that requires the following information to work: animals $<$ seed $><\#$ of objects>.

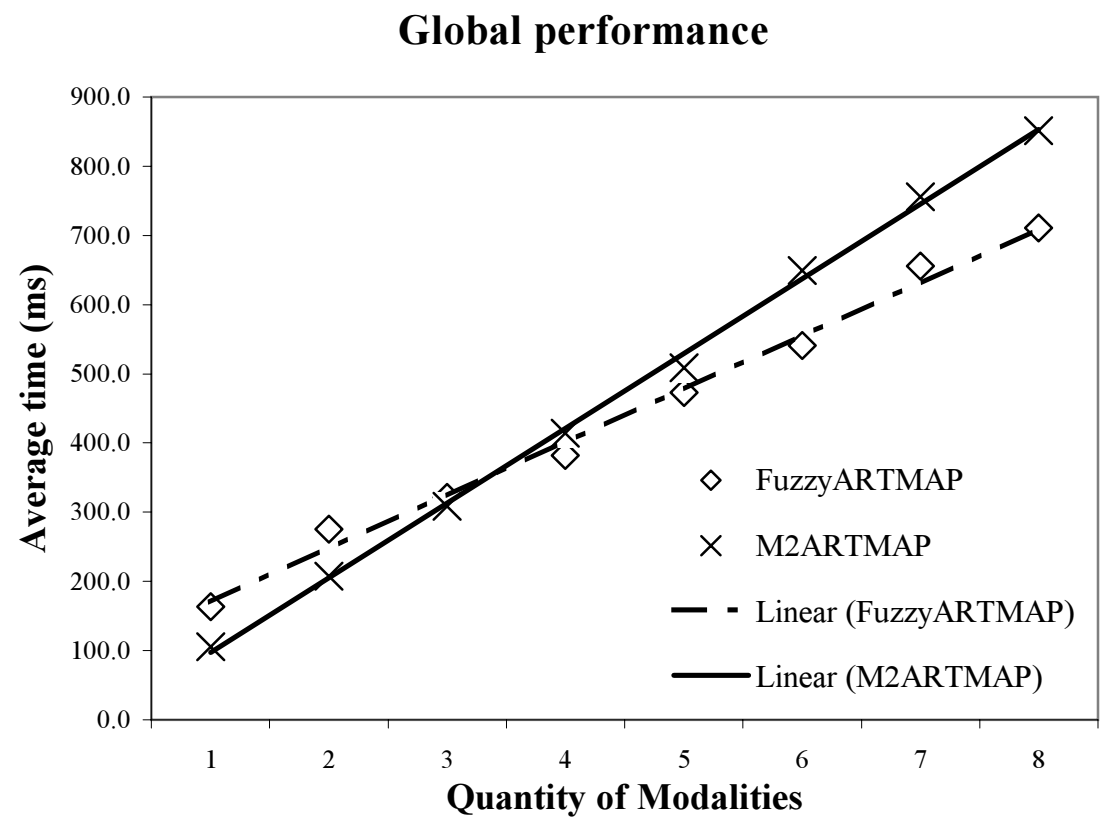

Figure 14. Performance comparison of Fuzzy ARTMAP vs. M2ARTMAP. (a) Training phase. (b) Testing phase. (C) Global performance

In the first set of simulations, both Fuzzy ARTMAP and M2ARTMAP where trained (in one epoch) and tested with the same set of 1000 exemplars produced with seed $=1278$. Both architectures achieved $100 \%$ prediction rates. 
In the next set of simulations, Fuzzy ARTMAP and M2ARTMAP where applied to a group of 384 subjects (91 variations of the choice parameter and 4 variations of the base vigilance), both architectures where trained (again in one epoch) using the set of 1000 exemplars produced with seed $=1278$ and tested using the set of 1000 exemplars produced with seed $=23941$. Once again, both achieved $100 \%$ prediction rates. Nevertheless, $\mathrm{M}_{2}$ ARTMAP's recognition rates where slower than expected. Thus, a t-Student paired test was conducted to constraint the difference between both architectures. It was confirmed that $\mathrm{M}_{2} \mathrm{ARTMAP}^{\prime} \mathrm{s}$ recognition rate was at most 5\% slower than Fuzzy ARTMAP's recognition rate, by rejecting the null hypothesis with a 1-tail $p$-value less than 0.0001 .

The global performance of the $\mathrm{M}_{2} \mathrm{ARTMAP}$ indicated that its performance it is superior when three or less modalities are used, which was considered acceptable since in a manufacturing environment is likely to encounter two or three modalities at most. The global comparison between $\mathrm{M}_{2}$ ARTMAP and the FuzzyARTMAP architecture is illustrated in Figure 14. (The reader is referred to (Lopez-Juarez, I. \& Ordaz-Hernandez, 2005) for complete details).

\section{Results from the implementation of the Distributed System.}

\subsection{General Description}

36 robotic assembly cycles were performed. Three modules were involved in the assessment SICT, SIRIO and SIEM. At the start of the operation SICT indicates to SIRIO to initialise the image processing in Zone 1, which corresponds to the area where the male component is grasped from the belt conveyor. Later this information is being sent to the SIEM which in turns moves the robot manipulator to pick up the component. At the same time the camera moves on the working space detecting the Zone 2, where the fixed, female component is located. This information is also sent to the SIRIO, to direct the robot towards the assembly point. Once the part is grasped and in contact with the female component the assembly operation is solely directed by the SIEM.

Table 3 contains the results from the 36 assembly cycles. The table provides information about the geometry of the component, chamfer, operation time, position error, based on the centroid location and the component rotation and finally the predicted type of assembly by the SIRIO module. 
Test for grasping the parts was made from zone 1 for each geometry. Each type was placed three times in the zone with $10^{\circ}$ orientation difference and four different locations.

In the assembly zone (zone 2) the location and orientation of the female component was constant. However, this information was never available to the SIEM or robot controller. So, every time this distance had to be calculated.

The first 18 assembly cycles were performed with chamfered female components and the remaining 18, without a chamfer. This can be observed in Table 3.

The total time corresponds to the assembly cycle, including insertion time, camera positioning, robot motion, image processing and home positioning. It is important to mention that all speeds were carefully chosen since it was a testing session. The system was later improved to work faster as it can be seen in (Corona-Castuera \& Lopez-Juarez, 2006). In this case for the assembly zone, there was always an initial error, to test the error recovery.

\begin{tabular}{|c|c|c|c|c|c|c|c|c|c|c|c|c|c|c|}
\hline \multirow[t]{2}{*}{ \# } & \multirow[t]{2}{*}{ Piece } & \multirow[t]{2}{*}{$\mathrm{Ch}$} & \multirow{2}{*}{$\begin{array}{l}\text { Time } \\
\text { (Min) }\end{array}$} & \multicolumn{3}{|c|}{ ZONE 1} & \multicolumn{3}{|c|}{ Error Zone 1} & \multicolumn{2}{|c|}{ ZONE 2} & \multicolumn{2}{|c|}{ Error Zone 2} & \multirow[t]{2}{*}{ Clasific. } \\
\hline & & & & $\mathrm{Xmm}$ & Ymm & $\mathrm{RZ}^{\circ}$ & $\mathrm{Xmm}$ & Ymm & $\mathrm{RZ}^{\mathrm{o}}$ & $\mathrm{Xmm}$ & Ymm & $\mathrm{Xmm}$ & Ymm & \\
\hline 1 & square & Yes & 1,14 & 57,6 & 143,1 & $0^{\circ}$ & 2,4 & 1,9 & 0 & 82,8 & 102,0 & 0,3 & 1,8 & square \\
\hline 2 & square & Yes & 1,19 & 56,6 & 44,8 & $12^{\circ}$ & 15,2 & 0,2 & 2 & 82,8 & 101,1 & 0,2 & 1,2 & square \\
\hline 3 & square & Yes & 1,13 & 172,8 & 46,7 & $23^{\circ}$ & 2,20 & $-1,7$ & 3 & 83,8 & 162,0 & $-0,9$ & 2,1 & square \\
\hline 4 & $\mathrm{rad}$ & Yes & 1,72 & 176,7 & 145,1 & $29^{\circ}$ & $-1,70$ & $-0,1$ & -1 & 79,6 & 103,0 & 3,9 & 2,9 & $\mathrm{rad}$ \\
\hline 5 & $\mathrm{rad}$ & Yes & 1,86 & 56,6 & 143,1 & $36^{\circ}$ & 3,4 & 1,9 & -4 & 82,8 & 103,0 & 0,6 & 2,9 & $\mathrm{rad}$ \\
\hline 6 & $\mathrm{rad}$ & Yes & 1,29 & 58,5 & 44,8 & $55^{\circ}$ & 15,2 & 0,2 & 5 & 80,7 & 102,0 & 1,5 & 2,3 & $\mathrm{rad}$ \\
\hline 7 & circle & Yes & 1,12 & 172,8 & 46,7 & $57^{\circ}$ & 2,20 & $-1,7$ & -3 & 82,8 & 101,1 & 0,4 & 1,2 & circle \\
\hline 8 & circle & Yes & 1,13 & 176,7 & 145,1 & $104^{\circ}$ & $-1,70$ & $-0,1$ & 34 & 83,8 & 103,0 & 0 & 3 & circle \\
\hline 9 & circle & Yes & 1,24 & 56,6 & 143,1 & $79^{\circ}$ & 3,4 & 1,9 & -1 & 79,6 & 102,0 & 3,2 & 2,2 & circle \\
\hline 10 & square & Yes & 1,7 & 56,6 & 42,8 & $66^{\circ}$ & 17,2 & 2,2 & -24 & 79,6 & 102,0 & 3,5 & 1,9 & square \\
\hline 11 & square & Yes & 1,22 & 172,8 & 45,7 & $123^{\circ}$ & 2,20 & $-0,7$ & 23 & 83,8 & 102,0 & -2 & 2,4 & square \\
\hline 12 & square & Yes & 1,93 & 178,7 & 144,1 & $110^{\circ}$ & $-3,70$ & 0,9 & 0 & 80,7 & 102,0 & 0 & 0 & square \\
\hline 13 & $\mathrm{rad}$ & Yes & 1,79 & 55,6 & 143,1 & $116^{\circ}$ & 4,4 & 1,9 & -4 & 82,8 & 102,0 & 1 & 2,4 & $\mathrm{rad}$ \\
\hline 14 & $\mathrm{rad}$ & Yes & 1,83 & 59,5 & 43,8 & $124^{\circ}$ & 16,2 & 1,2 & -6 & 80,7 & 103,0 & $-0,5$ & 2,3 & $\mathrm{rad}$ \\
\hline 15 & $\mathrm{rad}$ & Yes & 1,85 & 174,7 & 44,8 & $145^{\circ}$ & 0,30 & 0,2 & 5 & 82,8 & 102,0 & 1,8 & 3,1 & square \\
\hline 16 & circle & Yes & 1,76 & 176,7 & 147 & $143^{\circ}$ & $-1,70$ & -2 & -7 & 80,7 & 102,0 & $\begin{array}{l}-0,4 \\
\end{array}$ & 2,2 & circle \\
\hline 17 & circle & Yes & 1,21 & 57,6 & 144,1 & $164^{\circ}$ & 2,4 & 0,9 & 4 & 82,8 & 102,0 & 2,2 & 2,4 & circle \\
\hline 18 & circle & Yes & 1,23 & 60,5 & 45,7 & $175^{\circ}$ & 14,3 & $-0,7$ & 5 & 83,8 & 103,0 & $-0,3$ & 2,4 & circle \\
\hline 19 & square & No & 1,21 & 174,7 & 48,6 & $0^{\circ}$ & 0,30 & $-3,6$ & 0 & 81,7 & 103,0 & $-0,7$ & 3,3 & square \\
\hline 20 & square & No & 1,13 & 177,7 & 147 & $12^{\circ}$ & $-2,70$ & -2 & 2 & 82,8 & 103,0 & 0,5 & 1 & square \\
\hline 21 & square & No & 1,8 & 57,6 & 142,1 & $15^{\circ}$ & 2,4 & 2,9 & -5 & 83,8 & 102,0 & $-0,5$ & 0,8 & square \\
\hline 22 & $\mathrm{rad}$ & No & 1,84 & 61,5 & 45,7 & $26^{\circ}$ & 14,3 & $-0,7$ & -4 & 83,8 & 148,0 & $-1,6$ & $-0,2$ & $\mathrm{rad}$ \\
\hline 23 & $\mathrm{rad}$ & No & 1,26 & 175,7 & 49,6 & $36^{\circ}$ & $\begin{array}{l}-0,70 \\
\end{array}$ & $-4,6$ & -4 & 82,8 & 103,0 & $-2,7$ & 0,2 & $\mathrm{rad}$ \\
\hline 24 & $\mathrm{rad}$ & No & 1,21 & 179,6 & 147 & $49^{\circ}$ & $-4,60$ & -2 & -1 & 82,8 & 103,0 & $-1,7$ & 1,3 & $\mathrm{rad}$ \\
\hline 25 & circle & No & 1,13 & 59,5 & 147 & $63^{\circ}$ & 0,5 & -2 & 3 & 82,8 & 102,0 & $-1,1$ & 0,9 & circle \\
\hline 26 & circle & No & 1,2 & 61,5 & 46,7 & $84^{\circ}$ & 13,3 & $-1,7$ & 14 & 79,6 & 102,0 & $-1,7$ & 0,2 & circle \\
\hline 27 & circle & No & 1,11 & 176,7 & 49,6 & $77^{\circ}$ & $-1,70$ & $-4,6$ & -3 & 82,8 & 102,0 & 1,2 & 0,5 & circle \\
\hline 28 & square & No & 1,71 & 178,7 & 148 & $71^{\circ}$ & $-3,70$ & -3 & -19 & 81,7 & 103,0 & $-1,7$ & 0,1 & square \\
\hline 29 & square & No & 1,71 & 56,6 & 143,1 & $108^{\circ}$ & 3,4 & 1,9 & 8 & 79,6 & 103,0 & 0,6 & 0,9 & square \\
\hline 30 & square & No & 1,25 & 59,5 & 42,8 & $105^{\circ}$ & 17,2 & 2,2 & -5 & 83,8 & 102,0 & 13,2 & $-9,3$ & square \\
\hline 31 & $\mathrm{rad}$ & No & 1,71 & 174,7 & 46,7 & $116^{\circ}$ & 0,30 & $-1,7$ & -4 & 82,8 & 102,0 & 2,6 & 1,1 & $\mathrm{rad}$ \\
\hline 32 & $\mathrm{rad}$ & No & 2,88 & 176,7 & 146 & $131^{\circ}$ & $-1,70$ & -1 & 1 & 82,8 & 102,0 & $-2,1$ & 0,1 & $\mathrm{rad}$ \\
\hline 33 & $\mathrm{rad}$ & No & 1,82 & 57,6 & 143,1 & $131^{\circ}$ & 2,4 & 1,9 & -9 & 82,8 & 102,0 & $-1,8$ & 0,3 & $\mathrm{rad}$ \\
\hline 34 & circle & No & 1,28 & 58,5 & 43,8 & $145^{\circ}$ & 16,2 & 1,2 & -5 & 78,5 & 103,0 & $-1,8$ & 0,3 & circle \\
\hline
\end{tabular}




\begin{tabular}{|c|c|c|c|c|c|c|c|c|c|c|c|c|c|c|}
\hline \multirow[t]{2}{*}{$\#$} & \multirow[t]{2}{*}{ Piece } & \multirow[t]{2}{*}{$\mathrm{Ch}$} & \multirow{2}{*}{$\begin{array}{l}\text { Time } \\
\text { (Min) }\end{array}$} & \multicolumn{3}{|c|}{ ZONE 1} & \multicolumn{3}{|c|}{ Error Zone 1} & \multicolumn{2}{|c|}{ ZONE 2} & \multicolumn{2}{|c|}{ Error Zone 2} & \multirow[t]{2}{*}{ Clasific. } \\
\hline & & & & $\mathrm{Xmm}$ & Ymm & $\mathrm{RZ}^{\mathrm{o}}$ & $\mathrm{Xmm}$ & Ymm & $\mathrm{RZ}^{\circ}$ & $\mathrm{Xmm}$ & Ymm & $\mathrm{Xmm}$ & Ymm & \\
\hline 35 & circle & No & 1,14 & 174,7 & 46,7 & $164^{\circ}$ & 0,30 & $-1,7$ & 4 & 82,8 & 102,0 & $-2,8$ & 0,3 & circle \\
\hline 36 & circle & No & 1,16 & 176,7 & 146 & $170^{\circ}$ & $-1,70$ & -1 & 0 & 82,8 & 102,0 & 2,7 & 1,2 & circle \\
\hline
\end{tabular}

Table 3. Information of 36 assembly cycles for testing, with controlled speed

\subsection{Time in Information transfers}

During the testing session, different representative time transference was measured. This was accomplished using time counters located at the beginning and at the end of each process.

In the following graphs the 36 results are described . In Figure 15 a graph assembly vs time is shown. In the graph the timing between the data transfer between the imageCamera data to the iSIRIO it is shown. From bottom up, the first graph shows the timing SIRIO took to transfer the information in a matrix form; the following graph represents timing between the transfers of image information. The following graph shows the time the client SICT used to locate the image information to the visual component. Finally, the upper graph shows the total time for image transfer considering all the above aspects.

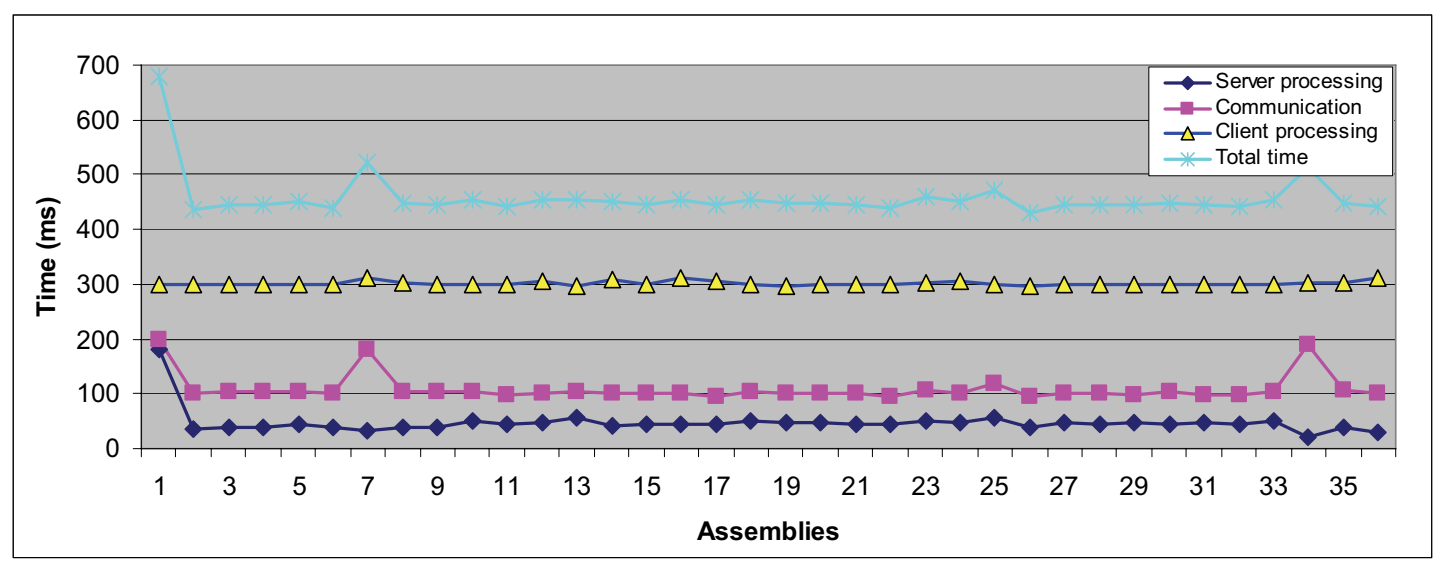

Figure 15. Transference of the information in the structure imageCamera of the SIRIO interface

Figure 16 shows the graphs corresponding to timing of the 36 operations for the transmission of pieceZone data type from the iSirio interface. The first graph from bottom up show the time that the Server took to locate the infor- 
mation in the structure pieceZone, the second graph shows the communication time and finally the total operation time.

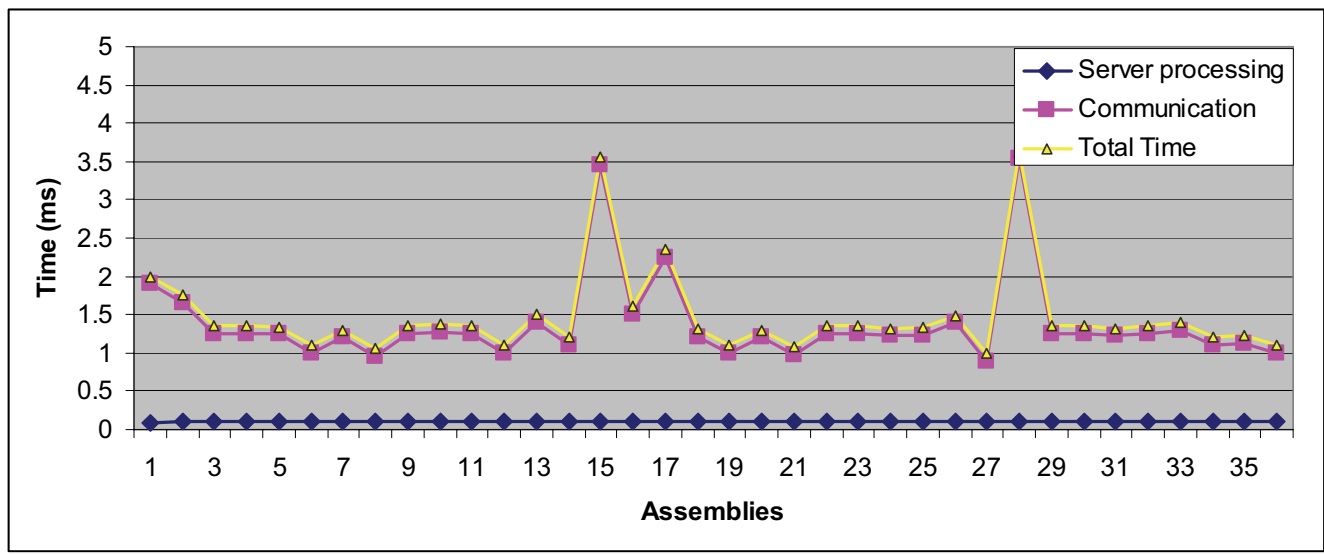

Figure 16. Transference of the information in the structure pieceZone of the SIRIO interface

Figure 17 shows the transference time of the sirioStatus data in the iSIRIO interface, where the first graph from bottom up represents the information transference time, the second graph represents the SIRIO processing time verify the camera status and the camera positioning system and finally the graph that represents the sum of both. It is important to mention that the timing is affected by the Server processing due to the process to verify the location of the positioning system.

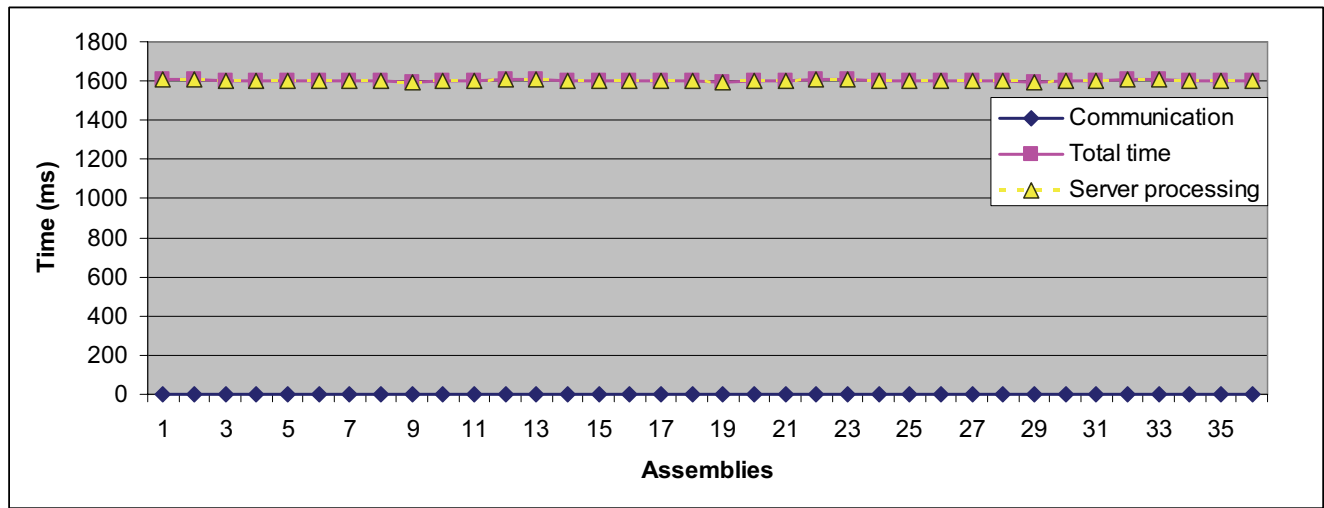

Figure 17. Transference of information in the structure sirioStatus of the SIRIO interface 
Finally, figure 18 shows the transference time from the F/T vector through the forcesReading data type from the interface iSIEM. The first graph from bottom up represents the communication times, the second, the time the SICT client took to show the information in visual components. The upper graph represents the time SIEM Server took to read the sensor information and finally a graph that represents the total time for each transference.

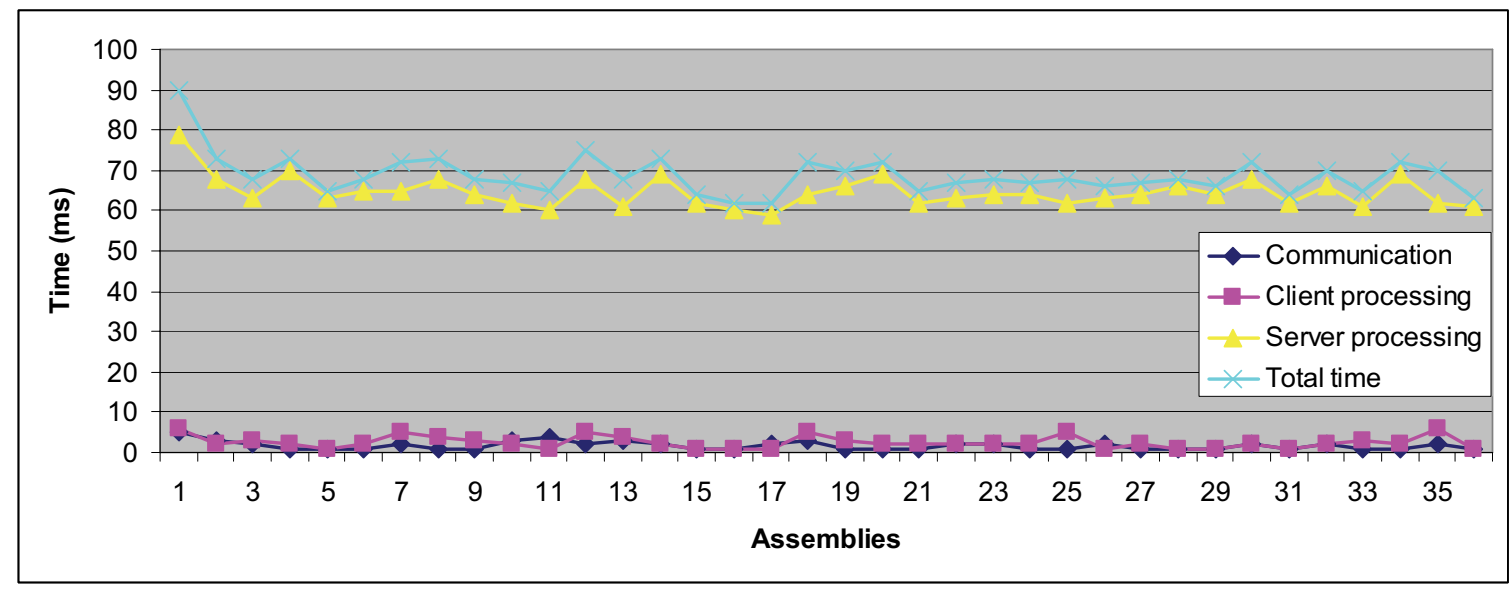

Figure 18. Transference of information in the structure forcesReading of the SIEM interface

\subsection{Failure Measurement}

We observed this point to statistically obtain the reliability of our system according to the performance of our system. In the 36 assemblies carried out, (18 chamfered and 18 chamferless), we obtained a 100\% success, in spite of the variety of the intercommunications and operations of the modules. During the 36 assembly cycles we did not register any event which caused the cycle to abort.

\subsection{Robot Trajectories in the Assembly Zone}

A robot trajectory describes the movements that the robot developed in the $X$, $\mathrm{Y}$ and $\mathrm{Rz}$ directions starting from an offset error to the insertion point. In Figure 19 the followed trajectories for the first 18 insertions during circular chamfered insertion are shown whereas in Figure 20 the corresponding trajectories for circular chamfered insertion are illustrated. In both cases a random offset was initially given. 


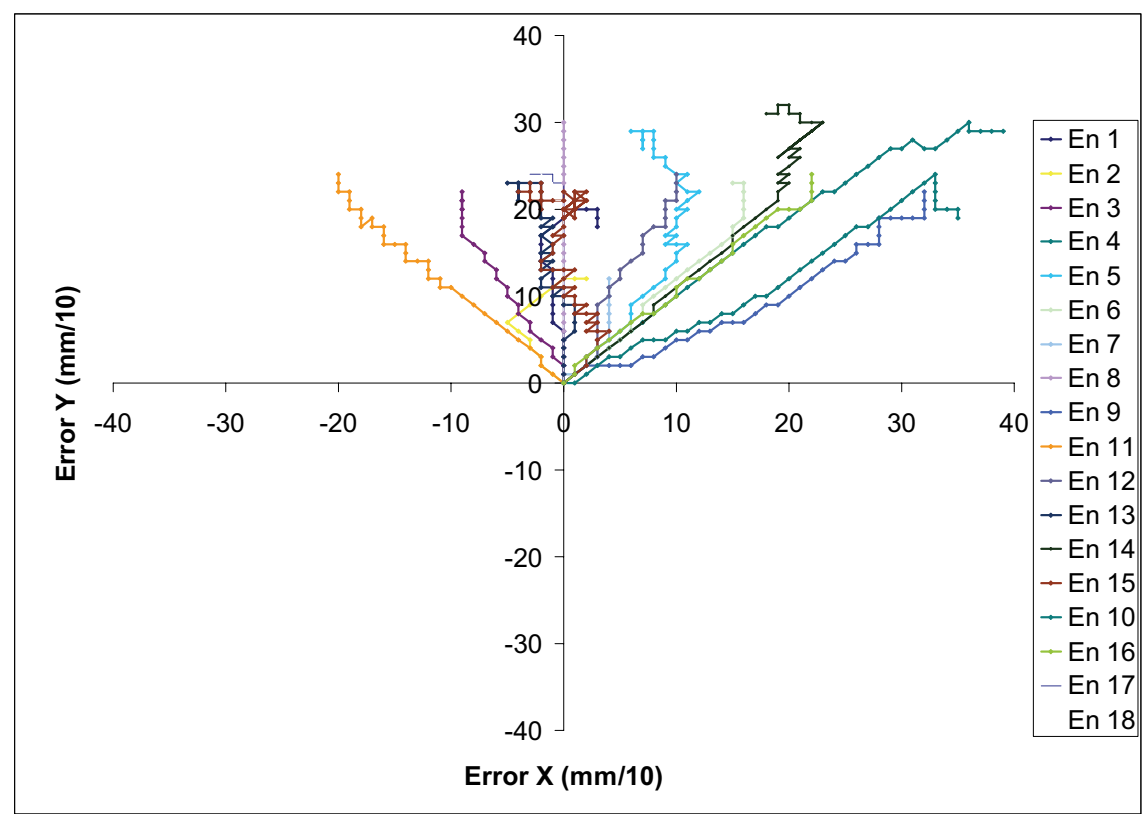

Figure 19. Trajectories for circular shamfered insertion

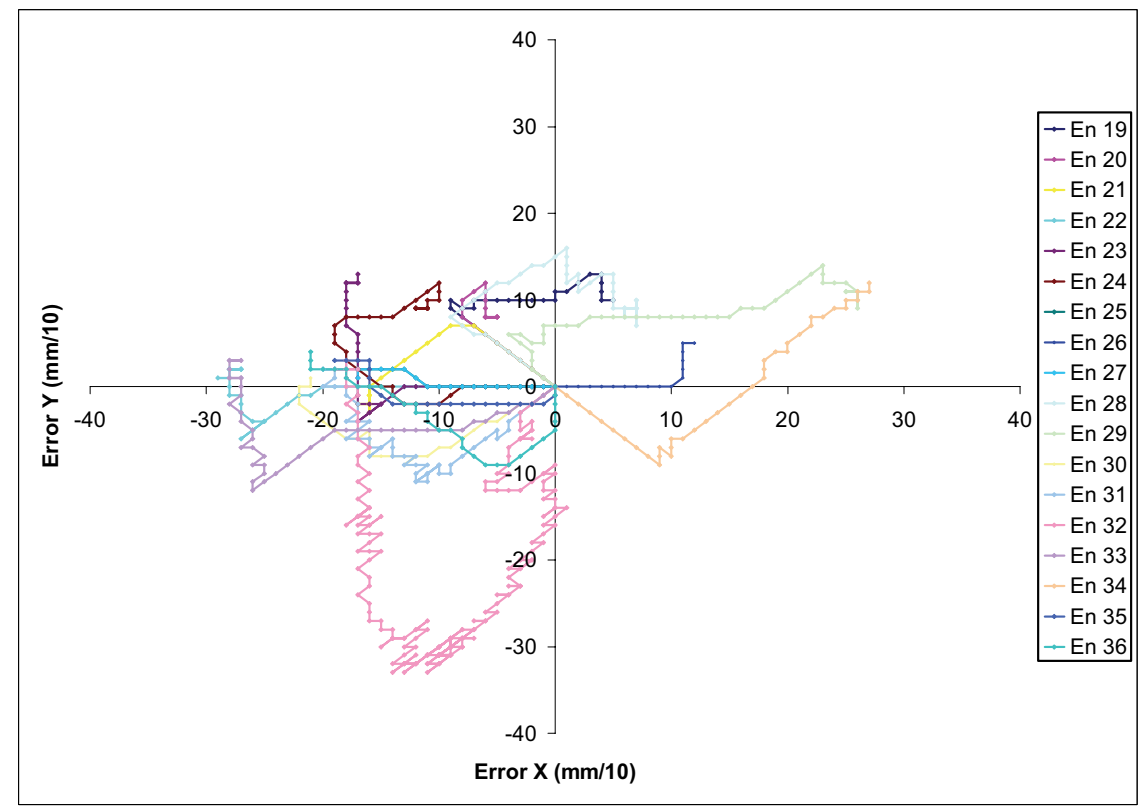

Figure 20. Trajectories for circular chamferless insertion 


\section{Conclusion and Future Work}

We have explained how the distributed system has been structured to perform robotic assembly operations aided by visual and contact force sensing information. The multimodal architecture $\mathrm{M}_{2} \mathrm{ARTMAP}$ was simulated in previous work, where global results motivated the implementation of the system by including visual and tactile information in two modules.

The current system has been tested in an intelligent manufacturing system. SIEM and SIRIO modules were incorporated successfully. Still further work is envisaged to fuse both visual and contact force sensing information as well as to include redundant and complementary information sensors.

\section{Acknowledgements}

The authors wish to thank the following organizations who made possible this research through different funding schemes: Deutscher Akademischer Austausch Dienst (DAAD), Consejo Nacional de Ciencia y Tecnologia (CONACyT) and the Consejo de Ciencia y Tecnologia del Estado de Queretaro. (CONCyTEQ).

\section{References}

Amoretti, Michele, Stefano Bottazzi, Monica Reggiani, Stefano Caselli., (2003). "Evaluation of Data Distribution Techniques in a CORBA-based Telerobotic System" Proc. of the 2003 IEEE/RSJ Intl. Conf. on Intelligent Robots and Systems (IROS 2003), October, Las Vegas, NV.

Amoretti, Michele, Stefano Bottazzi, Stefano Caselli, Monica Reggiani, (2004), "Telerobotic Systems Design based on Real-Time CORBA", Journal of Robotic Systems Volume 22, Issue 4 , PP. 183 - 201.

Asfour, Y.R., Carpenter, G.A., Grossberg, S., Lesher, G.W. (1993). Fusion ARTMAP: An adaptive fuzzy network for multi-channel classification. In: Third International Conference on Industrial Fuzzy Control and Intelligent Systems [IFIS-93], IEEE Press 155-160

Barney Dalton, Ken Taylor, (2000). "Distributed Robotics over the Internet", IEEE Robotics and Automation. 7(2): 22-27.

Bottazzi, S., S. Caselli, M. Reggiani, M. Amoretti, (2002). "A Software Framework based on Real-Time CORBA for Telerobotic Systems", Proceedings of 
the 2002 IEEE/RSJ Int. Conference on Intelligent Robots and Systems, EPFL, Lausanne, Switzerland, October.

Birney, Ewan, Michael Lausch, Todd Lewis, Stéphane Genaud, and Frank Rehberger (2003). ORBit Beginners Documentation V1.6

Carpenter, G.A., Grossberg, S., Iizuka, K. (1992a). Comparative performance measures of fuzzy ARTMAP, learned vector quantization, and back propagation for handwritten character recognition. In: International Joint Conference on Neural Networks. Volume 1., IEEE (1992) 794-799.

Carpenter, G.A., Grossberg, J., Markunzon, N., Reynolds, J.H., Rosen, D.B. (1992b). Fuzzy ARTMAP: a neural network architecture for incremental learning of analog multidimensional maps. IEEE Trans. Neural Networks Vol. 3 No. 5 678-713.

Carpenter, G.A., Streilein, W.W. (1998). ARTMAP-FTR: a neural network for fusion target recognition with application to sonar classification. In: AeroSense: Proceedings of SPIE's 12th Annual Symposium on Aerospace/Defense Sensing, Simulation, and Control. SPIE Proceedings, Society of Photo-Optical Instrumentation Engineers.

Corona-Castuera, J., I Lopez-Juarez, (2004). “Intelligent Task Level Planning for Robotic Assembly: Issues and Experiments" Mexican International Conference on Artificial Inteligence (MICAI'2004) Lecture Notes on Computer Science, Springer Verlag, ISBN 3-540-21459-3.

Corona-Castuera, J. \& Lopez-Juarez, I. (2006). Distributed Architecture for Intelligent Robotic Assembly, Part II: Design of the Task Planner. ADVANCED TECHNOLOGIES: Research-Development-Application. Submitted for publication.

Distributed Systems Research Group. "CORBA comparison Project", final report Charles University, Prague, Czech Republic. August 16, 1999.

Fernandez-Delgado, M., Barro Amereiro, S. (1998). MART: A multichannel artbased neural network. IEEE Transactions on Neural Networks 9 139-150

Ginnari, J.H., Langley, P., Fisher, D. (1992). : Quadruped mammals. Found as Quadruped Animals. Data Generator at UCI Machine Learning Repository http://www.ics.uci. edu/ mlearn/MLRepository.html.

Henning, Michi, Steve Vinoski, (2002). "Programación Avanzada en CORBA con C++", Addison Wesley, ISBN 84-7829-048-6.

Jia, Songmin, Yoshiro Hada, Gang Ye, Kunikatsu Takase, (2002). "Distributed Telecare Robotic Systems Using CORBA as a Communication Architec- 
ture" IEEE International Conference on Robotics \& Automation, Washington, DC.

Jia, Yoshiro Hada, Kunikatsu Takase, (2003). “Development of a Network Distributed Telecare Robotic System Using CORBA," Proceedings of the 2003 IEEE Int. Conference on Robotics, Intelligent Systems and Signal Processing, Changsha, China, October.

Lopez-Juarez, I; J. Corona-Castuera, M. Peña-Cabrera, K. Ordaz-Hernandez, (2005a), "On The Design of Intelligent Robotic Agents for Assembly", In special issue on Intelligent Embedded Agents", Journal of Information Sciences. Elsevier 171(2005) 377-402.

Lopez-Juarez, I.; K. Ordaz-Hernandez, M. Peña-Cabrera, J. Corona-Castuera and R. Rios-Cabrera, (2005b). "On The Design Of A Multimodal Cognitive Architecture for Perceptual Learning in Industrial Robots," Mexican Int. Conf. on Artificial Intelligence, (MICAI 2005), LNAI 3789, PP.1052-1061 Springer-Verlag Berlin Heidelberg.

Martens, S., Gaudiano, P., Carpenter, G.A. (1998). Mobile robot sensor integration with fuzzy ARTMAP. In: IEEE ISIC/CIRA/ISAS Joint Conference, IEEE

Object Management Group, (2000). The Common Object Request Broker: Architecture and Specification, Revision 2.4, October 2000.

Parsons, O., Carpenter, G.A. (2003). Artmap neural networks for information fusion and data mining: Map production and target recognition methodologies. Neural Networks 16.

Peña-Cabrera, Mario, Ismael Lopez Juarez, Reyes Rios Cabrera, Roman Osorio, (2004). “Un Proceso de Aprendizaje para Reconocimiento de Objetos en Línea en Tareas Robotizadas", 3" Conferencia Iberoamericana en Sistemas, Cibernética e Informática (CISCI 2004), Orlando, Florida, EE.UU., ISBN: 9806560-15-9.

Peña-Cabrera, M. \& Lopez-Juarez, I. (2006). Distributed Architecture for Intelligent Robotic Assembly, Part III: Design of the Invariant Object Recognition System. ADVANCED TECHNOLOGIES: Research-DevelopmentApplication. Submitted for publication.

Ríos-Cabrera R., Peña-Cabrera M., Goñi-Hernández F., Lopez-Juarez I., (2004a)., “Object Recognition Methodology for Part Grasping in a Manufacturing Cell", International Symposium on Robotics and Automation (ISRA'2004), Querétaro Qro., ISBN: 970-9702-00-9.

Ríos-Cabrera, R., (2004b). “Distribución de datos en una celda de manufactura flexible", Reporte interno CIATEQ, A.C. 2do. Sem. 2004, proy. 620088. 
Rios-Cabrera, R., Lopez-Juarez I., Corona-Castuera J, Chaparro-Sanchez R, Peña-Cabrera M, (2005). “Integración de Lenguaje Natural, Visión y Sensado de Fuerzas en una Celda de Manufactura Flexible", $4^{\underline{a}}$ Conferencia Iberoamericana en Sistemas, Cibernética e Informática (CISCI 2005), Orlando, Florida, EE.UU., ISBN: 980-6560-26-4

Thorpe, J., McEliece, R. (2002). Data fusion algorithms for collaborative robotic exploration. Progress Report 42-149, California Institute of Technology.

Yang, S., Chang, K.C. (1998). Multimodal pattern recognition by modular neural network. Optical Engineering 37. 650-659.

Wu, L., S. L. Oviatt, P. R. Cohen, (1999)., "Multimodal Integration - A Statical View", IEEE Transactions on Multimedia, vol 1 , Num. 4, pp 334-341. 


\section{Manufacturing}

the Future

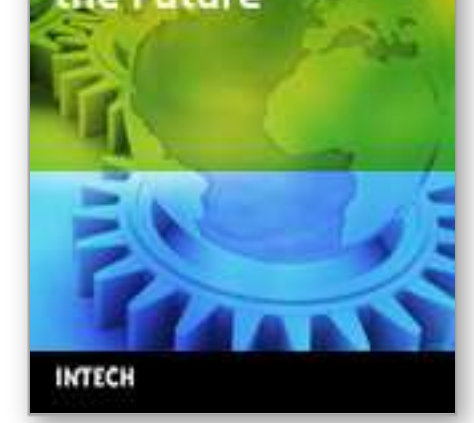

\section{Manufacturing the Future}

Edited by Vedran Kordic, Aleksandar Lazinica and Munir Merdan

ISBN 3-86611-198-3

Hard cover, 908 pages

Publisher Pro Literatur Verlag, Germany / ARS, Austria

Published online 01, July, 2006

Published in print edition July, 2006

The primary goal of this book is to cover the state-of-the-art development and future directions in modern manufacturing systems. This interdisciplinary and comprehensive volume, consisting of 30 chapters, covers a survey of trends in distributed manufacturing, modern manufacturing equipment, product design process, rapid prototyping, quality assurance, from technological and organisational point of view and aspects of supply chain management.

\section{How to reference}

In order to correctly reference this scholarly work, feel free to copy and paste the following:

Ismael Lopez Juarez and Reyes Rios Cabrera (2006). Distributed Architecture for Intelligent Robotic Assembly Part I: Design and Multimodal Learning, Manufacturing the Future, Vedran Kordic, Aleksandar Lazinica and Munir Merdan (Ed.), ISBN: 3-86611-198-3, InTech, Available from:

http://www.intechopen.com/books/manufacturing_the_future/distributed_architecture_for_intelligent_robotic_a ssembly_part_i_design_and_multimodal_learning

\section{INTECH}

open science | open minds

\section{InTech Europe}

University Campus STeP Ri

Slavka Krautzeka 83/A

51000 Rijeka, Croatia

Phone: +385 (51) 770447

Fax: +385 (51) 686166

www.intechopen.com

\section{InTech China}

Unit 405, Office Block, Hotel Equatorial Shanghai No.65, Yan An Road (West), Shanghai, 200040, China 中国上海市延安西路65号上海国际贵都大饭店办公楼 405 单元

Phone: +86-21-62489820

Fax: $+86-21-62489821$ 
(C) 2006 The Author(s). Licensee IntechOpen. This chapter is distributed under the terms of the Creative Commons Attribution-NonCommercial-ShareAlike-3.0 License, which permits use, distribution and reproduction for non-commercial purposes, provided the original is properly cited and derivative works building on this content are distributed under the same license. 